included many in the early stages of the disease. In 24 with stage I (clinically imperceptible) prostatic cancer high values of enzyme were detected in $12(50 \%)$ compared with $3(12 \%)$ using standard enzyme assay, while in 33 cases with stage II (palpable tumour confined within the gland) the corresponding ratio was $79 \%$ compared with $15 \%$. Nevertheless, raised values were also occasionally found in controls; some suffering from other forms of cancer, benign prostatic hyperplasia, and, surprisingly, after total prostatectomy. Many of these falsepositive results could be eliminated by raising the "cut-off" point of the test to $8.0 \mathrm{ng}$ per $0.1 \mathrm{ml}$ serum. With this modification, radioimmunoassay. remains considerably more accurate than standard enzyme assay.

The specificity and practical application of radioimmunoassay in diagnosing prostatic cancer may not be fully established yet, but the technique merits recognition. The raised values in other cancers, some patients with benign prostatic hyperplasia, and others who had previously undergone total prostatectomy suggests, however, that the method may not be entirely specific, possibly owing to the similarity of prostatic acid phosphatase to that from other sources. This has always been a problem with the biochemical tests; but one important difference may be that the radioimmunoassay must measure the immunological part of the molecule, which may not represent the biologically active part. Furthermore, though both techniques show more positive results with increasing spread of the disease, no relation has been established between phosphatase production and the malignancy of the tumour. As with any new screening test, only practical experience will show whether radioimmunoassay will prove to be of value to clinicians or whether it will remain of essentially academic interest.

${ }^{1}$ Foti, A G, et al, New England Fournal of Medicine, 1977, 297, 1357.

\section{Treatment of ankylosing spondylitis}

Most patients with ankylosing spondylitis never lose a day from work. In the past, misguided efforts to prevent spinal deformity encased victims in a plaster cast. The patients became inexorably bent, cracked the cast, and were left with fixed flexion deformities. We now know that this is the one rheumatic disease above all others that requires active exercises.

Yet, though the active approach is generally accepted, ${ }^{1-3}$ no formal clinical trial has ever evaluated such regimens. Clinicians at Bath (who are sufficiently interested to have sponsored the National Ankylosing Spondylitis Society) admit spondylitic patients for treatment and for intensive group physiotherapy in classes for three weeks. Other rheumatologists, with less cooperative patients, commonly organise a spondylitic clinic, where physiotherapists at regular intervals preach propaganda about exercises.

The Bath group found that 25 of 35 patients showed substantial improvement in neck movement with their regimen ${ }^{4}$ (lumbar spine lesions may cause more pain, but cervical spine changes cause more disability). Eleven patients seen three months after the course had improved further. The results of this interesting study raise many questions. Why did so many patients not respond? Were their spines already fixed and their condition irremediable? Why should they improve with regular exercise? Does exercise relieve pain and thus improve mobility-or was their analgesic regimen (not mentioned in the report) changed in hospital ?

For a condition with such a favourable natural course the doctor should limit treatment to agents that are not themselves worse than the disease. He must also emphasise the role of physical measures. The patient should sleep on a firm bed, with a pillow as small as possible. If he has a job in which he contorts himself for prolonged periods (for example, as a car mechanic), or if he is an assiduous clerk bent over his desk with never a moment to straighten his stiffening spine, then he should modify his pattern of work or find another occupation. He should avoid smoking, particularly to minimise the risk of chronic bronchitis, since he is likely to have severely restricted chest expansion.

The divided plaster bed, ${ }^{5}$ the halo splint, ${ }^{6}$ and skull traction ${ }^{7}$ have successfully reduced severe postural defects. Other appliances that may help patients with severe spondylitis include prismatic spectacles to extend a visual field limited by spinal rigidity and curvature; an adjustable mirror attached to the bed to give a better view of the surroundings; and a right-angled convex mirror device fixed to the car bonnet to improve vision to left and right, particularly at road junctions. ${ }^{2}$

Two of the best drugs for relieving pain and stiffness are indomethacin and phenylbutazone ${ }^{8}$ - and phenylbutazone may possibly modify the course of the disease. ${ }^{9}$ Flurbiprofen, ${ }^{10} 11$ sulindac, $^{3}$ and naproxen ${ }^{12}$ also have an effect. The most controversial form of treatment is radiotherapy. Physicians over 50 will testify to its effectiveness in many cases, but it has fallen almost totally into disuse because of the tenfold risk of leukaemia found in a large group of spondylitics so treated. ${ }^{13} 14$ Overall, however, this increased risk was small-certainly less than the risks of treatment with steroids. Indeed, the new edition of Davidson's Principles and Practice of Medicine ${ }^{15}$ still advocates the treatment in selected cases. The incidence of leukaemia after therapeutic or military radiation is related to the dose, ${ }^{16}$ and in a patient who does not respond to simple measures a single course of radiotherapy may well be the best treatment.

${ }^{1}$ Scott, J T, ed, Copeman's Textbook of Rheumatic Diseases, 5th edn. Edinburgh, Churchill Livingstone, 1978.

2 Wright, V, and Moll, J M H, Seronegative Polyarthritis, p 411. Amsterdam, North Holland Publishing Co, 1976.

${ }^{3}$ Calin, A, and Fries, J F, Ankylosing Spondylitis: Discussions in Patient Management. New York, Medical Examination Publishing Co, 1978.

${ }^{4}$ O'Driscoll, S L, Jayson, M I V, and Baddeley, H, Annals of the Rheumatic Diseases, 1978, 37, 64.

${ }^{5}$ Rose, G K, Rheumatism (London), 1961, 17, 63.

Perry, J and Nickel, V L, fournal of Bone and foint Surgery, 1959, 41A, 37.

Lee, M L H, Rheumatism (London), 1963, 19, 79.

${ }^{8}$ Godfrey, R G, et al, Arthritis and Rheumatism, 1972, 15, 110.

9 Boersma, J W, Scandinavian Fournal of Rheumatology, 1976, 5, 60.

10 Calin, A, and Grahame, R, British Medical fournal, 1974, 4, 496.

11 Sturrock, R D, and Hart, F D, Annals of the Rheumatic Diseases, 1974, 33, 129.

12 Hill, H F H, and Hill, A G S, Scandinavian fournal of Rheumatology, 1973, suppl 2, 121 .

${ }^{13}$ Court Brown, W M, and Abbatt, J D, Lancet, 1955, 1, 1283.

${ }^{14}$ Court Brown, W M, and Doll, R, British Medical fournal, 1965, 2, 1327.

${ }^{15}$ Duthie, J J R, and McCormick, J N, Davidson's Principles and Practice of Medicine, 12th edn, ed J Macleod, $p$ 636. Edinburgh, Churchill Livingstone, 1977.

${ }^{16}$ Spiers, F W, Radioisotopes in the Human Body-Physical and Biological Aspects, p 236. New York and London, Academic Press, 1968. 